\title{
Factors Affecting Nurses' Turnover in Alhassa Governmental Hospitals
}

\author{
Noora Yousef Al Soqair \\ Medical Assistance Services OC Administration in Directorate of Health Affairs in Alhassa Region, Ministry of Health in Saudi \\ Arabia, Alhassa, Saudi Arabia \\ Email: Noora055@live.com.au
}

How to cite this paper: Al Soqair, N.Y. (2021) Factors Affecting Nurses' Turnover in Alhassa Governmental Hospitals. Open Journal of Nursing, 11, 960-980. https://doi.org/10.4236/ojn.2021.1111078

Received: September 7, 2021

Accepted: November 22, 2021

Published: November 25, 2021

Copyright $\odot 2021$ by author(s) and Scientific Research Publishing Inc. This work is licensed under the Creative Commons Attribution International License (CC BY 4.0).

http://creativecommons.org/licenses/by/4.0/

\begin{abstract}
Nurse turnover can negatively impact delivering patient care in the health facilities which will affect the patient's health and reduce the quality of care. The $\mathrm{MOH}$ faces a serious challenge or high nursing staff turnover and the intention to leave the workforce. Aim: To explore one of the significant human recourse problems in the $\mathrm{MOH}$ and affecting the healthcare system, which is, factors affecting nurses' turnover in governmental hospitals using Alhassa governmental hospitals as a case study. Method: A quantitative research method used to explore the factors affecting nurses' turnover in the governmental hospitals in Alhassa. Result: According to the study finding, management style was a factor more likely to indicate nurses' turnover. It defines the impact of management style and works environment on nurses' and clients' systems. Individual factors were the second influence on their turnover. The balance between nurses' work and their family need was the first issue that had affected their work. Organization factors are also an influence on the nurses' turnover in Alhassa region. Conclusion: Nurses' turnover is a significant issue in a human resource in $\mathrm{MOH}$. This study first applied in Alhassa region that highlighted the factors that affect nurses' turnover. Nurses' turnover is a continuous problem that occurs in the health facilities related to management method causes, personal causes or organizational causes. Management style was the most influences on nurses' turnover in this study changing or modifying management style that can intent nurses to continue their work in the hospital in Alhassa region.
\end{abstract}

\section{Keywords}

Nurse Turnover, Turnover in Healthcare, Management Style, Individual Factors, Organization Factors, Work Environment, Turnover

\section{Introduction}

The health system in Saudi Arabia has been giving a high priority by the gov- 
ernment and it is one of the development areas identified in Saudi Arabia Vision 2030 [1]. Improving and developing the healthcare system in Saudi Arabia was clear in terms of quality and quantity of services in the past few years [2]. Nurses are one group of clinical professionals who can assist in optimizing healthcare delivery in health settings [3]. However, there were different barriers to impact implementing or continue developing the healthcare system. One of the most significant problems was nurse turnover in Saudi Arabia and many countries. Nurse turnover is defined as the movement of nurses from the organization voluntary or involuntary [4]. Nurse turnover can negatively impact delivering patient care in the health facilities which will affect the patient's health and reduce the quality of care. Furthermore, increasing nurse turnover rate in health facilities leads to insufficient staffing in the hospitals which escalate the workload and stress on other nurses. According to those changes and insufficient staffing in the facilities due to nurse turnover increasing infection rate, mortality rate, medication and medical errors will occur [5]. Several studies explored and discussed various influences that contribute to nurses' turnover in hospitals. It is a continuous problem that occurs in the health facilities related to personal causes or organizational causes. Poor work environment which includes lack of teamwork and communication, lack of social support, burnout and job dissatisfaction occurs frequently for nurses' hospitals which lead to a turnover. Job dissatisfaction is frequently recognized as the main cause of nurse turnover [6] [7] [8].

The Saudi Arabia's Ministry of Health $(\mathrm{MOH})$ plays a vital role in healthcare delivery. It provides an estimated $60 \%$ of all healthcare services through various hospitals located in different parts of the kingdom [9]. In the effort to accomplish the mission of having a healthy population, the $\mathrm{MOH}$ has been investing in infrastructural developments while implementing various challenges, policies, and approaches. It currently operates 2281 primary healthcare (PHC) centers. In 2014, the MOH employed 18,136 nurses, 9304 physicians, and 9690 allied health workers. The numbers have been improving since 2010. Unfortunately, an increasing number of nurses are involved in non-nursing roles, including management. Consequently, the $\mathrm{MOH}$ suffers a scarcity of nurses to undertake the crucial roles [9].

\subsection{Problem Statement}

The $\mathrm{MOH}$ faces a serious challenge or high nursing staff turnover and the intention to leave the workforce. The problem of a low ratio of nurses to patients is experienced in Saudi Arabia (SA). Research has found that expatriate nurses in SA have an average stay of 2.2 years in the workforce [10]. About $50 \%$ of nurses in SA are expatriates or foreigners. For that reason, factors such as lack of cultural competence and the need to search for better working environment could have a great role in the high turnover rates. The issue of nurse turnover is contributing to SA failing to achieve the recommended nurse to patient ratio. Data shows that the ratio of nurses (including midwives) to patients in SA is 4.867 per 
1000 patients. This ratio is lower than the recommended five nurses for every 1000 patients, although it shows that the SA government is on the verge of reaching the target [11].

Several other factors contribute to the high turnover intentions among nurses in SA. A study conducted by [11], revealed that low salaries, old age, several years of experience, and working position contribute to high rate of staff turnover. Nurses in clerical and supervisory supervision were highly likely to leave the current employment. These and other factors have a direct and indirect effect of influencing nurses to leave the $\mathrm{MOH}$ for the private sector while others are seeking employment in other areas and countries [11].

Staff turnover is one of the main human resource (HR) issues or challenges facing organizations. The workforce is arguably one of the main resources for any given organization, especially in the service delivery sector, including the healthcare field. For that reason, establishing and maintaining a highly competitive workforce in terms of numbers, skills, competencies, personalities, inherent motivation or drive, and ability to deliver high quality and safe healthcare services is essential for the $\mathrm{MOH}$. However, the organization is facing high levels of staff turnover and intent to leave the workplace [12].

The issue of nurse turnover is having negative effects on $\mathrm{MOH}$. Most importantly, it is leading to massive drainage of skills, knowledge, and experience, a considerable rise in HR costs, especially hiring, training, and development, and loss of MOH's competitiveness [13]. The human capital plays a leading role in the operational efficiency, service quality, and competitiveness of an organization [14]. Consequently, the continued loss of human capital is detrimental to the short, medium, and long-term goals of the institution. The problem will hinder the Saudi Arabian government through the $\mathrm{MOH}$ from achieving healthcare-related goals and vision [15].

\subsection{Aim}

This research aims to explore one of the significant human recourse problems in the Ministry of Health in Saudi Arabia and affecting the healthcare system, which is, factors affecting nurses' turnover in governmental hospitals using Alhassa governmental hospitals as a case study. This study examines the factors that contribute to the increase of turnover among nurses in Alhassa governmental hospitals. Understanding these factors could assist $\mathrm{MOH}$ to find solutions that can help nurses in their career retention.

\subsection{Literature Review}

One of the most significant problems was nurse turnover in Saudi Arabia and many countries [5]. Nurses turnover define as the movement of nurses from the organization voluntary or involuntary [4]. Nurse turnover can negatively impact delivering patient care in the health facilities which will affect the patient's health and reduce the quality of care. Furthermore, increasing nurse turnover rate in 
health facilities leads to insufficient staffing in the hospitals which escalate the workload and stress on other nurses. According to those changes and insufficient staffing in the facilities due to nurse turnover increasing infection rate, mortality rate, medication and medical errors will occur [5]. Several studies explore and discussed various influences that contribute to nurses' turnover in hospitals. It is a continuous problem occurring in the health facilities related to personal causes or organizational causes. Poor work environment which includes lack of teamwork and communication, lack of social support, burnout and job dissatisfaction occur frequently for nurses in the hospital which leads to a turnover. Job dissatisfaction is frequently recognized as the main cause of nurse turnover [6] [7] [8].

\section{The influence of organization factors on Nurses' Turnover}

There are other variables also have a relationship on nurse turnover includes the organization system, management style, workload, empowerment, role perceptions and individual factors [7]. In the literature, the organizational factors emphasized the psychosocial work environment as one of the main influences on nurses' turnover. It includes leader supports, trust, motivation, and rewards all those factors if it is not applied in the workplace can impact negatively nurses which leads to a turnover. Unclear rewards system or inadequate could impact negatively nurses which leads to leaving the job [7] [16]. However, workload occurs in the organization which causes burnout and stress for nurses. Nurse turnover affects negatively in practice and reduces the quality of care. Also, nurses' performance was decline due to workload which leads to leaving the job [7]. Feeling unsafe work environment also can impact on nurses' performance and intention to continue their work. Work safety is essential for nurses and other healthcare providers to administer care to the client in a proper method [17].

H1: There is a relationship between organization factors and nurses' turnover. The influence of Management style on Nurses' Turnover

The first influences that cause a negative impact in work environments are a lack of leaders' support and lack of teamwork in the organization [18]. In another study, a lack of psychological work environment was associated with nurse turnover because it is withdrawn of social life and relationship in the work environment which increase the conflict [19]. Management style, leadership style, continues support and effective management methods can assist in creating a positive work environment [20]. Some research found that nurse turnover is influenced by leaders and supervisors more than their colleagues in the workplace [7] [19] [21]. Good nurse managers could create a positive work environment which impacts on nurse staff by improving performance and quality of care. Absence of support or direct communication with staff nurses leads to increase stress at work and inappropriate management style can also affect nurses' performance. Low-quality teamwork was associated with increased intent to leave the job, career development opportunity, quality of social relations and influences at work. These outcomes are consistent with another study in which nurses 
that planned to leave their job reported greater odds with nurses' managers, the absence of their support and their leadership style [19] [21].

H2: There is a relationship between management style and nurses' turnover.

\section{The influence of Individual factors on Nurses' Turnover}

There were individual factors associated with nurse turnover. In the recent study shows there was an inverse relevance among nurses' age and intention to turnover. New and young nurses want to gain further qualifications that improve their career whereas old generation nurse they tend to be committed to their hospitals and work [22]. The year of experiences also correlates negatively in nurse turnover intention. Lack of challenges in the organization especially for new nurses causes the intention to turnover because as a new staff looking for career development [23] [24]. Besides, the salary and payment that nurses have in the organization could be the main factors for nurse turnover for some nurses. The financial benefits influence turnover intention [7]. According to a study done in Saudi Arabia found financial benefits and motivations such as increase salary or overtime payment could assist in decreasing the nurse turnover. The workload in hospitals and emergency departments could occur due to nurses' shortage which makes nurses working extra time without financial benefits. This action collaborates to increase turnover among nurses in Saudi. The workplace environment also impacts negatively on intention nurses' turnover in Saudi [5] [10]. Furthermore, working hours and rotations schedule can impact negatively on nurses because they do not have the energy to take care of their children after work. Nurses shift working can affect on family life and decrease the ability for nurses to administer care for their elderly and their children [25].

H3: There is a relationship between individual factors and nurses turnover.

The ministry of health in Saudi Arabia is facing a problem of nurse turnover, which is preventing the country from achieving the recommended ratio of nurses to patients. Organizational, personal, and environmental factors are contributing to high nurse turnover. Most importantly, organizational issues such as low pay, discrimination, unsupportive leadership, poor accommodation, and burnout are leading to low levels of job satisfaction and commitment, thereby contributing to high nurse turnover rates. The problem has a negative impact on healthcare quality and safety. Based on the above previous studies that discussed the factors that affecting on nurses' turnover, the suggested hypotheses can be illustrated in the research conceptual framework for the factors affecting nurses' turnover in Alhassa governmental hospitals (see Figure 1).

\section{Methodology}

\subsection{Research Design}

A research design is a strategy that applied in the study to plan the method that the study be carried out. A quantitative study method's main goal is to provide specific facts and estimate from a large and representative sample of respondents that decision-makers can apply to understand the relationship, differences, verify 


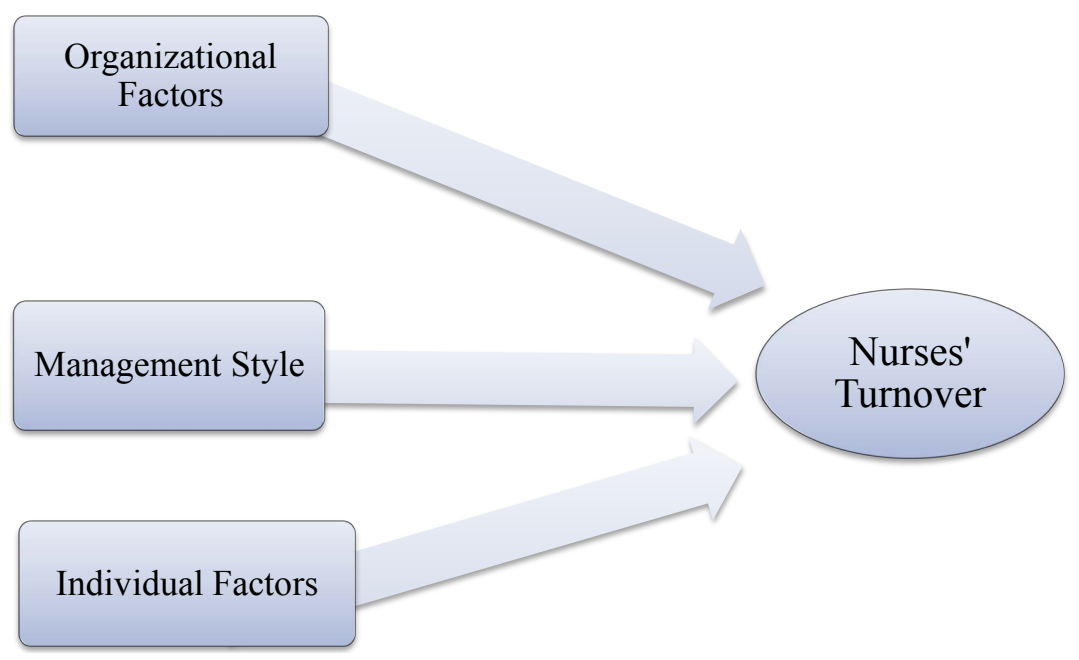

Figure 1. A conceptual model on the factors affecting Nurses' turnover in Alhassa Governmental Hospitals.

and validate the existing relationship. A quantitative study method applied to conduct this study to explore the factors affecting nurses' turnover in the governmental hospital in Alhassa.

\subsection{Research Method}

A quantitative research method used to explore the factors affecting nurses' turnover in the governmental hospitals in Alhassa. This study focuses on the specific question that needed to be answered. These factors were described in the hypotheses.

\subsection{Population}

The study was conducted on nurses who are working in the governmental hospital in Alhassa. The total nurses who are working in the governmental hospitals in Alhasaa are large to study (2957 nurses) so, the sample of the participants randomly selected from the population of 10 hospitals. All nurses who participate in the study completed questionnaires that were distributed among the random sample.

\section{Inclusion Criteria}

1) Nurses working in governmental hospitals

2) Saudi and non-Saudi nurses are included

3) Governmental hospital in Alhassa region only

\section{Exclusion Criteria}

1) Privet hospitals are excluded

2) All governmental hospital not in Alhassa region

\subsection{Sampling}

Simple random sampling was conducted in the study. The sample was selected from 10 governmental hospitals in Alhassa. All nurses were invited to complete 
the questionnaires.

\subsection{Data Collection Method}

All data were collected to gather all the information required to finish the study. A structured questionnaire utilized to obtain the data relevant to the study. The questionnaire selected according to the literature review. Questionnaire pre-testing conducted before distribution to determine the feasibility of using the instrument. The questionnaire includes demographical data, organizational factors, management style factors and individual factors. The questionnaire items included questions that aim to identify the factors affecting nurses' turnover in Alhassa governmental hospitals.

\subsection{The Research Instruments}

Questionnaires were used to answer the objective of this research. The questionnaire has two main parts. The first part about demographical information includes gender, age, level of educations, years of experience. Two instrument that used in this research first instrument is Brooks' survey of quality nurses' work life (QNWL) [26]. This questionnaire contains 42 items in four subclasses which are work life/home life, work design, work context and work the world. All items included in the questionnaire answered the research question and related to the independent variables. The work life/home life dimension defined the interface between the life experiences of nurses in the work and home. Also, it defined the interaction nurses; work and their life at home and career planning. The work design dimension defined the nature of nursing work, decision making, autonomy, nursing workload, delegation and job satisfaction. The third dimension is work context which contains work environment, stress, management style, scheduling, shift work, teamwork, feedback on performance and recognition from managers. The last dimension is the work world which defines health care policy, labor markets and changes in educational requirements. The second instrument Anticipated Turnover Scale (ATS), it contains 12 items. It is self-administered survey aims to examine nurses' turnover intention. ATS questionnaire measure nurses' attitudes and perception regarding their current job and their probability of terminating their job. It is related to an employees' anticipated length of time to leave and certainty of leaving the job [27]. Both instruments asked nurses to respond to how much they agree or disagree with each item on a 6 points scale, " 1 " indicate strongly disagree and " 6 " indicate strongly agree [26] [27].

\subsection{Data Analysis}

Data were analyzed after been collected to give meaning to the numbers. Analyzing the data was conducted by using Statistical Package for the Social Sciences (SPSS).

\subsection{Ethical Consideration}

An ethical issue was considered in this study. The nurses were asked their per- 
mission before participating in the study and they have the right to refused to participate in the study. Also, all hospital acceptance considered before conducting the study. All data were treated in confidential and anonymous manners.

\section{Result}

\subsection{Sample Profile}

The questionnaire was distributed to 260 nurses working in the governmental hospital in Alhassa region. The respondents' majority were female $(n=213$, $81.9 \%$ ) while male respond was less $(\mathrm{n}=47,18.1 \%)$. There were four age groups in the population of the study. One hundred and seven participants, representing $41.2 \%$ of the population were aged 30 - 39 years old, while seventy-five individuals, representing $28.8 \%$ were aged 20 - 29 years old. The participants' whose ages 40 - 49 years old were present $22.3 \%$ of the population while $7.7 \%$ of the population were aged 50 - 59 years old. The study was targeted all nurses working in the governmental hospitals in Alhassa region with different nationality either Saudi or non-Saudi. The respondents present Saudi nurses were the majority (55\%), on other hand non-Saudi nurses present (45\%) of the population. The demographic data also were distinguished the married statues with three groups including never married, married and divorces/widowed. Also, the demographic data included if the nurses have dependent children or/and adults. The result shows one hundred and eighty nine of nurses are married with a percentage of (76.5\%) of the population, while fifty-one of nurses were never married with a percent of (19.6\%) and only (3.8\%) of nurses were divorced or widowed. Dependent children and/or adult were also questioned and the responses were one hundred and forty-one which present (54.2\%) of the population have dependent children and one hundred and forty-eight with (56.9\%) do not have dependent adult. However, one hundred and nineteen nurses do not have dependent children $(45.8 \%)$ and $(43.1 \%)$ of nurses have dependent adult. Education level was one of the variables that been questioned to the participants and the result shows $56.9 \%$ of nurses awarded with bachelor degree or higher while $43.1 \%$ of nurses having diploma degree. Nurses experience in their career, organizational and position were measured by classifying it to three categories. One hundred and forty-one nurses their experience in nursing were more than ten years, which was the majority $54.2 \%$ of the population. After that, nurses who were expert from five to nine years were $23.1 \%$ and who were expert less than four years were the less $22.7 \%$. Although, organizational and positional experience were measured with similar categorization and the result was $38.5 \%$ of nurses have more than ten years' experience in their organization and $39.2 \%$ have less than four years of experience in their position. The result also shows the experience in the organization from five to nine years is $31.2 \%$ of nurses and in the position, is $32.2 \%$. Most nurses' salary per month was S.R 5000 to 10,000 (55\%) of nurses and more than 10,000 S.R comes after with (31.2\%) as shown in (Table 1). 
Table 1. Demographic data.

\begin{tabular}{|c|c|c|c|}
\hline \multicolumn{2}{|c|}{ Variables } & Frequency & Percent \\
\hline \multirow{2}{*}{ Gender } & Male & 47 & 18.1 \\
\hline & Female & 213 & 81.9 \\
\hline \multirow{4}{*}{ Age } & $20-29$ Years & 75 & 28.8 \\
\hline & $30-39$ Years & 107 & 41.2 \\
\hline & $40-49$ Years & 58 & 22.3 \\
\hline & $50-59$ Years & 20 & 7.7 \\
\hline \multirow{3}{*}{ Married Status } & Never Married & 51 & 19.6 \\
\hline & Married & 199 & 76.5 \\
\hline & Divorced/Widowed & 10 & 3.8 \\
\hline \multirow{2}{*}{ Nationality } & Saudi & 143 & 55 \\
\hline & Non-Saudi & 117 & 45 \\
\hline \multirow{2}{*}{ Dependent Children } & Yes & 141 & 54.2 \\
\hline & No & 119 & 45.8 \\
\hline \multirow{2}{*}{ Dependent Adult } & Yes & 112 & 43.1 \\
\hline & No & 148 & 56.9 \\
\hline \multirow{2}{*}{ Education Level } & Diploma & 112 & 43.1 \\
\hline & Bachelor or Higher & 148 & 56.9 \\
\hline \multirow{3}{*}{ Nursing Experience } & Less than 4 Years & 59 & 22.7 \\
\hline & 5 - 9 Years & 60 & 23.1 \\
\hline & More than 10 Years & 141 & 54.2 \\
\hline \multirow{3}{*}{$\begin{array}{l}\text { Organizational } \\
\text { Experience }\end{array}$} & Less than 4 Years & 79 & 30.4 \\
\hline & 5 - 9 Years & 81 & 31.2 \\
\hline & More than 10 Years & 100 & 38.5 \\
\hline \multirow{3}{*}{ Positional Experience } & Less than 4 Years & 102 & 39.2 \\
\hline & 5 - 9 Years & 84 & 32.3 \\
\hline & More than 10 Years & 74 & 28.5 \\
\hline \multirow{3}{*}{ Payment Per Month } & Less than 5000 SR & 36 & 13.8 \\
\hline & SR $5000-10,000$ & 143 & 55.0 \\
\hline & More than 10 SR & 81 & 31.2 \\
\hline
\end{tabular}

\subsection{Descriptive Statistics}

The nurses who participate in this study were asked to answer Brooks' survey of quality nurses' work life (QNWL) [26]. All nurses included in this study are working in governmental hospitals in Alhassa Region. This questionnaire contains 42 items in four factors in its original form, after doing Exploratory Factor Analysis (EFA), the results shows that we have three factors (Table 2), as following: 
Table 2. Factor analysis for QNWL 42 items.

\begin{tabular}{|c|c|c|c|c|c|}
\hline & $\begin{array}{l}\text { Item } \\
\text { number }\end{array}$ & QNWL items & $\begin{array}{c}\text { Factor } \\
\text { load }\end{array}$ & $\begin{array}{l}\text { explained } \\
\text { variance }\end{array}$ & $\begin{array}{l}\text { explained } \\
\text { total variance }\end{array}$ \\
\hline \multirow{17}{*}{ 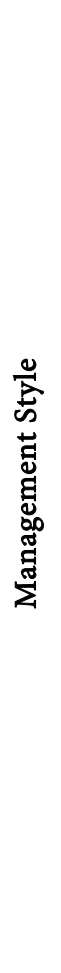 } & 29 & The nurses' lounge/break area/locker room in my setting is comfortable. & 0.822 & \multirow{17}{*}{20.999} & \multirow{17}{*}{20.999} \\
\hline & 28 & I feel respected by physicians in my work setting. & 0.822 & & \\
\hline & 27 & I am able to participate in decisions made by my nurse manager/supervisor. & 0.708 & & \\
\hline & 18 & I am able to communicate well with my nurse manager/supervisor. & 0.697 & & \\
\hline & 30 & I have access to degree completion programs through my work setting. & 0.680 & & \\
\hline & 36 & I feel safe from personal harm (physical, emotional, or verbal) at work. & 0.655 & & \\
\hline & 33 & I am recognized for my accomplishments by my Nurse manager/supervisor. & 0.652 & & \\
\hline & 34 & Nursing policies and procedures facilitate my work. & 0.645 & & \\
\hline & 19 & I have adequate patient care supplies and equipment. & 0.603 & & \\
\hline & 37 & I feel that upper-level management has respect for nursing. & 0.596 & & \\
\hline & 20 & My nurse manager/supervisor provides adequate supervision. & 0.575 & & \\
\hline & 38 & I believe that, in general, society has the correct image of nurses. & 0.574 & & \\
\hline & 31 & I receive support to attend in-services and continuing education programs. & 0.547 & & \\
\hline & 23 & I feel like there is teamwork in my work setting. & 0.540 & & \\
\hline & 26 & I receive feedback on my performance from my nurse manager/supervisor. & 0.538 & & \\
\hline & 24 & I feel like I belong to the "work family". & 0.503 & & \\
\hline & 22 & My work setting provides career advancement opportunities. & 0.501 & & \\
\hline \multirow{9}{*}{ 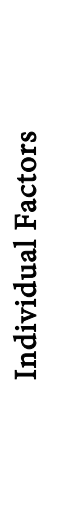 } & 5 & My organization's policy for family-leave time is adequate. & 0.706 & \multirow{9}{*}{11.252} & \multirow{9}{*}{32.251} \\
\hline & 7 & I am able to arrange for day care when my child is ill. & 0.695 & & \\
\hline & 6 & I am able to arrange for day care for my elderly parents. & 0.678 & & \\
\hline & 8 & I receive a sufficient amount of assistance from unlicensed support personnel. & 0.619 & & \\
\hline & 2 & I am able to arrange for child-care when I am at work. & 0.615 & & \\
\hline & 15 & There are enough RNs in my work setting. & 0.607 & & \\
\hline & 3 & I have energy left after work. & 0.544 & & \\
\hline & 17 & I receive quality assistance from unlicensed support personnel. & 0.541 & & \\
\hline & 1 & I am able to balance work with my family needs. & 0.504 & & \\
\hline \multirow{7}{*}{ 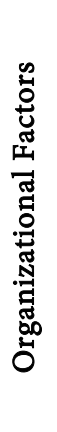 } & 13 & I experience many interruptions in my daily work routine. & 0.651 & \multirow{7}{*}{9.901} & \multirow{7}{*}{42.152} \\
\hline & 41 & I feel my job is secure. & 0.576 & & \\
\hline & 10 & My workload is too heavy. & 0.536 & & \\
\hline & 14 & I have enough time to do my job well. & 0.533 & & \\
\hline & 40 & $\begin{array}{l}\text { I would be able to find the same job in another organization with about the } \\
\text { same salary and benefits. }\end{array}$ & 0.531 & & \\
\hline & 42 & I believe my work impacts the lives of patients/families. & 0.514 & & \\
\hline & 16 & I am able to provide good quality patient care. & 0.514 & & \\
\hline
\end{tabular}

Initially, the factorability of the 42 items was examined. Several well-recognized criteria for the factorability of a correlation were used. 
Firstly, it was observed that 33 of the 42 items correlated at least 0.50 with at least one other item, suggesting reasonable factorability.

Secondly, the Kaiser-Meyer-Olkin measure of sampling adequacy was .84, above the commonly recommended value of .6, and Bartlett's test of sphericity was significant $\left(\chi^{2}(861)=7459.814, \mathrm{p}<0.05\right)($ Table 3$)$.

Finally, the communalities were all above 0.50 , further confirming that each item shared some common variance with other items. Given these overall indicators, factor analysis was deemed to be suitable with all 42 items. Principal components analysis was used because the primary purpose was to identify and compute composite scores for the factors underlying the QNWL. Initial Eigen values indicated that the three factors explained $21 \%, 11 \%$, and $10 \%$ of the variance respectively (Table 3 ).

A total of (9) items were eliminated because they did not contribute to a simple factor structure and failed to meet a minimum criteria of having a primary factor loading of 0.50 or above.

The first subclass in the QNWL will be examined the second hypothesis which related to management style. It was ranking according to the respondents and it shows question number 20 (My nurse manager/supervisor provides adequate supervision) was number one in the rank with mean $=4.29$ and $\mathrm{SD}=1.41$ as show in (Table 4).

The second rank with mean $=4.28$ and $\mathrm{SD}=1.32$, was for question number 34 in the survey (Nursing policies and procedures facilitate my work). Question number 18 (I am able to communicate well with my nurse manager/supervisor) was the third in the ranking (mean $=4.22, \mathrm{SD}=1.45$ ). However, the last three questions were as following: question 19 (I have adequate patient care supplies and equipment) was ranked the 15 th (mean $=3.73, \mathrm{SD}=1.54)$ and question number 28 (I feel respected by physicians in my work setting) was ranked the 16th (mean $=3.53, \mathrm{SD}=1.72$ ), and the last in the ranking in this subclass was question number 29 (The nurses' lounge/break area/locker room in my setting is comfortable) $($ mean $=3.53, \mathrm{SD}=1.72)$ as shown in (Table 4$)$.

The second dimension in the QNWL was the third hypothesis which related to Individual factors and contains 7 questions that answered by the participants and ranking according to the highest mean as shown in Table 5. The first three questions in the rank were as following: question one (I am able to balance work with my family needs) (mean $=3.78, \mathrm{SD}=1.56)$ and in the second was question number 5 in the QNWL survey (My organization's policy for family-leave time is adequate) (Mean $=3.60, \mathrm{SD}=1.68)$. Then, question number two was the third

Table 3. KMO and Bartlett's test of Sphericity.

\begin{tabular}{lcc}
\hline \multicolumn{2}{c}{ Kaiser-Meyer-Olkin Measure of Sampling Adequacy. } & 0.840 \\
\hline & Approx. Chi-Square & 7459.814 \\
Bartlett's Test of Sphericity & df & 861 \\
& Sig. & 0.000 \\
\hline
\end{tabular}


Table 4. Descriptive statistics (Management style Factor).

\begin{tabular}{|c|c|c|c|c|}
\hline & Management Style Factors & Mean & Std. Deviation & rank \\
\hline Q18 & I am able to communicate well with my nurse manager/supervisor. & 4.22 & 1.45 & 3 \\
\hline Q19 & I have adequate patient care supplies and equipment. & 3.73 & 1.54 & 15 \\
\hline Q20 & My nurse manager/supervisor provides adequate supervision. & 4.29 & 1.41 & 1 \\
\hline Q22 & My work setting provides career advancement opportunities. & 4.20 & 1.55 & 5 \\
\hline Q23 & I feel like there is teamwork in my work setting. & 4.13 & 1.45 & 7 \\
\hline Q24 & I feel like I belong to the "work family". & 4.21 & 1.35 & 4 \\
\hline Q26 & I receive feedback on my performance from my nurse manager/supervisor. & 4.13 & 1.43 & 8 \\
\hline Q27 & I am able to participate in decisions made by my nurse manager/supervisor. & 4.06 & 1.63 & 10 \\
\hline Q28 & I feel respected by physicians in my work setting. & 3.53 & 1.72 & 16 \\
\hline Q29 & The nurses' lounge/break area/locker room in my setting is comfortable. & 3.53 & 1.72 & 17 \\
\hline Q30 & I have access to degree completion programs through my work setting. & 3.87 & 1.58 & 13 \\
\hline Q31 & I receive support to attend in-services and continuing education programs. & 4.12 & 1.57 & 9 \\
\hline Q33 & I am recognized for my accomplishments by my Nurse manager/supervisor. & 4.20 & 1.46 & 6 \\
\hline Q34 & Nursing policies and procedures facilitate my work. & 4.28 & 1.32 & 2 \\
\hline Q36 & I feel safe from personal harm (physical, emotional, or verbal) at work. & 3.87 & 1.57 & 14 \\
\hline Q37 & I feel that upper-level management has respect for nursing. & 3.94 & 1.57 & 12 \\
\hline Q38 & I believe that, in general, society has the correct image of nurses. & 3.97 & 1.69 & 11 \\
\hline
\end{tabular}

Table 5. Descriptive statistics (Individual Factor).

\begin{tabular}{|c|c|c|c|c|}
\hline & Individual Factors & Mean & Std. Deviation & Rank \\
\hline Q1 & I am able to balance work with my family needs. & 3.78 & 1.56 & 1 \\
\hline Q2 & I am able to arrange for child-care when I am at work. & 3.54 & 1.69 & 3 \\
\hline Q3 & I have energy left after work. & 3.45 & 1.78 & 4 \\
\hline Q5 & My organization's policy for family-leave time is adequate. & 3.60 & 1.68 & 2 \\
\hline Q6 & I am able to arrange for day care for my elderly parents. & 3.31 & 1.62 & 6 \\
\hline Q7 & I am able to arrange for day care when my child is ill. & 3.04 & 1.68 & 8 \\
\hline Q8 & I receive a sufficient amount of assistance from unlicensed support personnel. & 2.99 & 1.76 & 9 \\
\hline Q15 & There are enough RNs in my work setting. & 3.28 & 1.79 & 7 \\
\hline Q17 & I receive quality assistance from unlicensed support personnel. & 3.36 & 1.78 & 5 \\
\hline
\end{tabular}

(I am able to arrange for child-care when I am at work) (mean $=3.54, \mathrm{SD}=$ 1.69).

However, the last three questions in the rank were as following: in the seventh order was question number 15 (There are enough RNs in my work setting) ( mean $=3.28, \mathrm{SD}=1.79)$. The eighth rank was for question number seven ( $\mathrm{I}$ am able to arrange for day care when my child is ill) (mean $=3.04, \mathrm{SD}=1.68)$ and the ninth was question number 8 (I receive a sufficient amount of assistance 
from unlicensed support personnel) $($ mean $=2.99, \mathrm{SD}=1.76)$, as shown in (Table 5).

The first hypothesis in the study was related to organization factors and contains 7 questions were dimension in the QNWL that answered by the participants and ranking according to the highest mean as shown in (Table 6). The first three questions in the rank were as following: question 42 (I believe my work impacts the lives of patients/families) (mean $=4.53, \mathrm{SD}=1.22$ ) and in the second was question number 16 in the QNWL survey (I am able to provide good quality patient care) $($ Mean $=4.33, \mathrm{SD}=1.28)$. Then, question number 41 was the third (I feel my job is secure) (mean $=4.26, \mathrm{SD}=1.45$ ).

However, the last three questions in the rank were as following: in the fifth order was question number 14 (I have enough time to do my job well) (mean = $4.10, \mathrm{SD}=1.48$ ). The sixth rank was for question number 13 (I experience many interruptions in my daily work routine) (mean $=4.08, \mathrm{SD}=1.60$ ) and the seventh was question number 40 (I would be able to find the same job in another organization with about the same salary and benefits) (mean $=3.99, \mathrm{SD}=1.60$ ), as shown in (Table 6).

The three hypothesis examined weather there was a relationship between nurses turnover and organization factor, management styles and individual factors which included in QNWL instruments. The study result shows there were significant positive relationship between each factor of QNWL and total score of QNWL $(\mathrm{p}<0.05)$ as shown in (Table 7) below.

The second instrument that applied in this research was ATS which examine the high in tendency among nurses to leave their current job. Table 8 below shows the means and standard deviations of ATS items,

The first three questions in the rank were as following: question number 5 (If I got another job offer tomorrow, I would give it serious consideration) (mean = $4.24, \mathrm{SD}=1.47$ ) and in the second was question number 2 in the ATS survey (I am quite sure I will leave my position in the foreseeable future) (Mean $=3.95$, $\mathrm{SD}=1.31$ ). Then, question number 7 was the third (I have been in my position about as long as I want to) (mean $=3.85, \mathrm{SD}=1.21$ ).

Table 6. Descriptive statistics (Organization factor).

\begin{tabular}{|c|c|c|c|c|}
\hline & Organization Factors & Mean & Std. Deviation & Rank \\
\hline Q10 & My workload is too heavy. & 4.16 & 1.44 & 4 \\
\hline Q13 & I experience many interruptions in my daily work routine. & 4.08 & 1.60 & 6 \\
\hline Q14 & I have enough time to do my job well. & 4.10 & 1.48 & 5 \\
\hline Q16 & I am able to provide good quality patient care. & 4.33 & 1.28 & 2 \\
\hline Q40 & $\begin{array}{l}\text { I would be able to find the same job in another organization with about the same } \\
\text { salary and benefits. }\end{array}$ & 3.99 & 1.60 & 7 \\
\hline Q41 & I feel my job is secure. & 4.26 & 1.45 & 3 \\
\hline Q42 & I believe my work impacts the lives of patients/families. & 4.53 & 1.22 & 1 \\
\hline
\end{tabular}


Table 7. Relationship between QNWL factors and QNWL total score.

\begin{tabular}{cccc}
\hline Factors & & QNWL total score & Hypothesis \\
\hline \multirow{2}{*}{ Management Style } & Pearson Correlation & $0.915^{* *}$ & Supported \\
& P value & 0.000 & \\
Individual & $\mathrm{N}$ & 260 & \\
& Pearson Correlation & $0.768^{* *}$ & Supported \\
& P value & 0.000 & \\
\hline \multirow{2}{*}{ Organizational } & $\mathrm{N}$ & 260 & \\
& Pearson Correlation & $0.639^{* *}$ & \\
& $\mathrm{P}$ value & 0.000 & \\
& $\mathrm{~N}$ & 260 & \\
\hline
\end{tabular}

Table 8. ATS items means and SD.

\begin{tabular}{|c|c|c|c|}
\hline ATS & Mean & Std. Deviation & Rank \\
\hline Q1. I plan to stay in my position. & 2.86 & 1.4 & 12 \\
\hline Q2. I am quite sure I will leave my position in the foreseeable future. & 3.95 & 1.31 & 2 \\
\hline Q3. Deciding to stay or leave my position is not a critical issue for me at this point in time. & 3.22 & 1.21 & 10 \\
\hline Q4. I know whether or not I will be leaving this center within a short term. & 3.53 & 1.36 & 6 \\
\hline Q5. If I got another job offer tomorrow, I would give it serious consideration. & 4.24 & 1.47 & 1 \\
\hline Q6. I have no intention of leaving my present position. & 3.31 & 1.44 & 9 \\
\hline Q7. I have been in my position about as long as I want to. & 3.85 & 1.21 & 3 \\
\hline Q8. I am certain I will be staying here. & 3.37 & 1.29 & 8 \\
\hline Q9. I don't have any specific idea how much longer I will stay. & 2.87 & 1.26 & 11 \\
\hline Q10. I plan to hang on to this job. & 3.45 & 1.25 & 7 \\
\hline Q11. There are big doubt in my mind as to whether or not I will really stay in this center. & 3.69 & 1.08 & 4 \\
\hline Q12. I plan to leave this position shortly. & 3.58 & 1.37 & 5 \\
\hline
\end{tabular}

However, the last three questions in the rank were as following: in the 10th order was question number 3 (Deciding to stay or leave my position is not a critical issue for me at this point in time) (mean $=3.22, \mathrm{SD}=1.21$ ). The 11 th rank was for question number 9 (I don't have any specific idea how much longer I will stay) (mean $=2.87, \mathrm{SD}=1.26$ ) and the 12 th was question number 1 (I plan to stay in my position) (mean $=2.86, \mathrm{SD}=1.4$ ), as shown in (Table 8 ).

As study results show no significant relationship between QNWL factors and ATS scale ( $\mathrm{p}>0.05)$ as shown in Table 9 below.

Table 10 below shows that the reliability coefficient was 0.92 for management style 0.84 for individual factors 0.75 for organizational factors and 0.93 for overall questionnaire, all these coefficients indicates high reliability. Also, different studies show like this study the reliability and result of Cronbach's alpha is 0.90 [2] [5]. 
Table 9. Relationship between QNWL factors and ATS scale.

\begin{tabular}{ccc}
\hline QNWL factors & Total ATS \\
\hline Management Style & Pearson Correlation & -0.019 \\
& P value & 0.764 \\
\hline Individual & Pearson Correlation & -0.018 \\
& P value & 0.776 \\
\hline Organizational & Pearson Correlation & 0.024 \\
& P value & 0.702 \\
\hline Total QNWL & Pearson Correlation & -0.013 \\
& P value & 0.838 \\
\hline
\end{tabular}

Table 10. Reliability and validity.

\begin{tabular}{lcccc}
\hline & $\begin{array}{c}\text { Management } \\
\text { Style }\end{array}$ & $\begin{array}{c}\text { Individual } \\
\text { Factors }\end{array}$ & $\begin{array}{c}\text { Organizational } \\
\text { Factors }\end{array}$ & Total \\
\hline $\mathrm{N}$ (number of items) & 17 & 9 & 7 & 33 \\
$\begin{array}{l}\text { Average Variance Extracting } \\
\text { (AVE) }\end{array}$ & 0.40 & 0.38 & 0.31 & 0.36 \\
$\begin{array}{l}\text { Cronbach's alpha } \\
\text { (Composite Reliability) }\end{array}$ & 0.92 & 0.84 & 0.75 & 0.93 \\
\hline
\end{tabular}

On the other hand, the discriminant validity for the 3 factors was calculated as shown in Table 10, the Average variance extract for management style was 0.40 , for individual factors was 0.38 , for organizational factors was 0.31 , and for overall questionnaire was 0.36. According to Fornell \& Larcker [28], in case of AVE is less than 0.5 but composite reliability is higher than 0.6 , the convergent validity of the construct is still adequate. Therefore, the questionnaire that applied in this study is valid.

\section{Discussion}

Nurses' turnover in Saudi Arabia is a significant human resource problem for all hospitals and other countries [4]. This research aims to explore the factors affecting nurses' turnover in Alhassa governmental hospitals because other studies discuss this issue among nurses in Saudi but it is the first time to be studied in Alhassa region. The sample of this study was 260 nurses working in the 10 governmental hospitals in Alhassa Region with a different nationality. The participants' Saudi nurses were the majority 55\%, on other hand non-Saudi nurses present $45 \%$ of the population and most of the participant were female nurses. The objective of this study is to explore the relationship between organizational factors, management style and individual factors. This study found there was a relationship between those factors and nurses' turnover. This study confirms that organizational factors, management style and individual factors had a posi- 
tive impact on nurses' turnover in the governmental hospital in Alhassa region. It appears from the finding there was no significant relationship between QNWL factors and ATS scale.

According to the study finding management style was a factor more likely to indicate nurses' turnover. It defines the impact of management style and works environment on nurses and clients' systems [29]. The first item that was the first in ranking and the most effect on nurses' turnover was the supervision style and control of nurses by their managers or supervisors in their work. Furthermore, strategies and policies that are applied in the facility as well as the communication method with supervisors and managers have a negative impact as founded in this study. As previous studies found that nurse turnover is influenced by managers and supervisors in the workplace and it can increase turnover among nurses [7] [19] [21].

As stated by the respondents of the study individual factors were the second influence on their turnover. The balance between nurses' work and their family need was the first issue that been affected their work. Working shifts according to the organization policy and the long working hours away from their family. As well as fulfillment for childcare for their children when they are at work also influence their turnover. As most of the respondents in this study are females and nurses are primarily female this can reflect the role of the mother. According to Brook and Anderson [25], the study argued that nurses unable to balance between their work and family needs and the rotated work schedule impact negatively in their life. Moreover, the absence of childcare or inability to arrange for nurses' children childcare when they are at work is another influence affecting nurses' turnover [30].

Organization factors are also an influence on the nurses' turnover in Alhassa region. The majority of the participants in this study were satisfied with how nurses have a positive impact on clients and their families' life. They found themselves they are administering proper care to the patients according to their condition, as well as their feeling of security in their job in the workplace. On other hands, the workload is too heavy which can affect their turnover intention. Various previous studies argued the workplace safety also can influence turnover among nurses and it is a significant issue considered in the organization [31]. As violence against healthcare providers and specifically nurses are major occupational issues that have been discussed in different studies and their impact on healthcare workers [32]. Nurses' safety feelings at the workplace can impact their performance and intention to continue working. According to a previous study conducted in Alhassa regarding violence against healthcare providers in primary healthcare. It founds $28 \%$ of the sample were exposed to at least one of the violence incident during the past year on the study. A safe work environment enhances healthcare provider performance and increases their safety feeling in their workplace. The quality of care can be affected if the workplace not safely working environment [17]. 


\section{Conclusion}

In conclusion, nurses' turnover is a significant issue in a human resource in $\mathrm{MOH}$. This study first applied in Alhassa region that highlighted the factors that affect nurses' turnover. Nurses' turnover is a continuous problem that occurs in the health facilities related to management method causes, personal causes or organizational causes. Management style was the most influences on nurses' turnover in this study changing or modifying management style that can intent nurses to continue their work in the hospital in Alhassa regions. The individual factors and the balance between work and family needs can contribute to nurse turnover. Finally, organization factors have less impact than other factors in nurses' turnover. Considering all causes that can influence in increasing the number of nurses' turnover can contribute to the reduction of nurses' turnover in Alhassa Region.

\section{Acknowledgements}

I would like to express my deep love and gratitude to my family, my husband, my son, my mother and my brothers for their love, tremendous support, encouragement, patience, appreciation, understanding and trust. Finally, I would like to pray and thank my Father (GOD Bless HIM) for his love, support and encouragement from the begging of my journey until now.

\section{Conflicts of Interest}

The author declares no conflicts of interest regarding the publication of this paper.

\section{References}

[1] Bassi, J. and Bugis, S. (2020) KSA: Vision 2030 Update in Relation to Healthcare. Tamimi \& Co., Jeddah.

[2] Almalki, M., FitzGerald, G. and Clark, M. (2011) The Nursing Profession in Saudi Arabia: An Overview. International Nursing Review, 58, 304-311. https://doi.org/10.1111/j.1466-7657.2011.00890.x

[3] Fougere, B., Morley, J.E., Decavel, F., Nourhashemi, F., Abele, P., Resnick, B., et al. (2016) Development and Implementation of the Advanced Practice Nurse Worldwide with an Interest in Geriatric Care. Journal of the American Medical Directors Association, 17, 782-788. https://doi.org/10.1016/j.jamda.2016.05.009

[4] Kovner, C.T., Jun, J., Brewer, C.S. and Fatehi, F. (2014) What Does Nurse Turnover Rate Mean and What Is the Rate? Policy, Politics, and Nursing Practice, 15, 64-71. https://doi.org/10.1177/1527154414547953

[5] Kaddourah, B., Abu-Shaheen, A.K. and Al-Tannir, M. (2018) Quality of Nursing Work Life and Turnover Intention among Nurses of Tertiary Care Hospitals in Riyadh: A Cross-Sectional Survey. BMC Nursing, 17, Article No. 43. https://doi.org/10.1186/s12912-018-0312-0

[6] Christiani, L. and Ilyas, J. (2018) Factors Affecting Nurse Turnover in Hospitals: A Literature Review. Addressing Global Health Challenges. Policy, Research and Practices, No. 3, 191-230. 
[7] Hayes, L.J., O’Brien-Pallas, L., Duffield, C., Shamian, J., Buchan, J., Hughes, F., et al. (2012) Nurse Turnover: A Literature Review-An Update. International Journal of Nursing Studies, 49, 887-905. https://doi.org/10.1016/j.ijnurstu.2011.10.001

[8] Hayes, L.J., O’Brien-Pallas, L., Duffield, C., Shamian, J., Buchan, J., Hughes, F., et al. (2006) Nurse Turnover: A Literature Review. International Journal of Nursing Studies, 43, 237-263. https://doi.org/10.1016/j.ijnurstu.2005.02.007

[9] Al Asmri, M., Almalki, M.J., Fitzgerald, G. and Clark, M. (2019) The Public Healthcare System and Primary Care Services in Saudi Arabia: A System in Transition. East Mediterranean Health Journal, 25, 468-476. https://doi.org/10.26719/emhj.19.049

[10] Aljohani, K.A. and Alomari, O. (2018) Turnover among Filipino Nurses in Ministry of Health Hospitals in Saudi Arabia: Causes and Recommendations for Improvement. Annals of Saudi Medicine, 38, 140-142. https://doi.org/10.5144/0256-4947.2018.140

[11] Al-Ahmadi, H. (2014) Anticipated Nurses' Turnover in Public Hospitals in Saudi Arabia. International Journal of Human Resource Management, 25, 412-433. https://doi.org/10.1080/09585192.2013.792856

[12] Karatepe, O.M. and Vatankhah, S. (2014) The Effects of High-Performance Work Practices on Perceived Organizational Support and Turnover Intentions: Evidence from the Airline Industry. Journal of Human Resources in Hospitality \& Tourism, 13, 103-119. https://doi.org/10.1080/15332845.2014.847292

[13] Maden, C. (2014) Impact of Fit, Involvement, and Tenure on Job Satisfaction and Turnover Intention. The Service Industries Journal, 34, 1113-1133. https://doi.org/10.1080/02642069.2014.939644

[14] Battistoni, E., Bonacelli, A., Colladon, F.A. and Schiraldi, M.M. (2013) An Analysis of the Effect of Operations Management Practices on Performance. International Journal of Engineering Business Management, 5, 1-11. https://doi.org/10.5772/56919

[15] Pasban, M. and Nojedeh, S.H. (2016) A Review of the Role of Human Capital in the Organization. Procedia-Social and Behavioral Sciences, 230, 249-253. https://doi.org/10.1016/j.sbspro.2016.09.032

[16] Li, J., Mueller, B.H., Hasselhorn, H.M., Fu, H., Shang, L., Hu, Y., et al. (2010) Psychosocial Work Environment and Intention to Leave the Nursing Profession: Results from the Longitudinal Chinese NEXT Study. Scandinavian Journal of Public Health, 38, 69-80. https://doi.org/10.1177/1403494809354361

[17] El-Gilany, M. and El-Wehady, A., Amr, M. (2010) Violence against Primary Health Care Workers in Al-Hassa, Saudi Arabia. Journal of Interpersonal Violence, 25, 716-734. https://doi.org/10.1177/0886260509334395

[18] Tei-Tominaga, M., and Miki, A. (2010) A Longitudinal Study of Factors Associated with Intentions to Leave among Newly Graduated Nurses in Eight Advanced Treatment Hospitals in Japan. Industrial Health Industrial Health, 48, 305-316. https://doi.org/10.2486/indhealth.48.305

[19] Leiter, M.P. and Maslach, C. (2009) Nurse Turnover: The Mediating Role of Burnout. Journal of Nursing Management, 17, 331-339. https://doi.org/10.1111/j.1365-2834.2009.01004.x

[20] Gormley, D.K. (2011) Are We on the Same Page? Staff Nurse and Manager Perceptions of Work Environment, Quality of Care and Anticipated Nurse Turnover. Journal of Nursing Management, 19, 33-40. https://doi.org/10.1111/j.1365-2834.2010.01163.x 
[21] Rondeau, K.V., Williams, E.S. and Wagar, T.H. (2009) Developing Human Capital: What Is the Impact on Nurse Turnover? Journal of Nursing Management, 17, 739-748. https://doi.org/10.1111/j.1365-2834.2009.00988.x

[22] Dasgupta, P. (2018) Turnover Intentions among Nurses in Private Hospitals: Antecedents and Mediators. Journal of Strategic Human Resource Management, 4, 1-15. https://doi.org/10.21863/jshrm/2015.4.3.014

[23] Delobelle, P., Rawlinson, J.L., Ntuli, S., Malatsi, I., Decock, R. and Depoorter, A.M. (2011) Job Satisfaction and Turnover Intent of Primary Healthcare Nurses in Rural South Africa: A Questionnaire Survey. Journal of Advanced Nursing, 67, 371-383. https://doi.org/10.1111/j.1365-2648.2010.05496.x

[24] Trybou, J., Malfait, S., Gemmel, P. and Clays, E. (2015) Nursing Staff and Their Team: Impact on Intention to Leave. International Nursing Review, 62, 489-496. https://doi.org/10.1111/inr.12216

[25] Brooks, B.A. and Anderson, M.A. (2004) Nursing Work Life in Acute Care. Journal of Nursing Care Quality, 19, 269-275. https://doi.org/10.1097/00001786-200407000-00014

[26] Brooks, B.A., Storfjell, J., Omoike, O., Ohlson, S., Stemler, I., Shaver, J. and Brown, A. (2007) Assessing the Quality of Nursing Work Life. Nursing Administration Quarterly, 31, 152-157. https://doi.org/10.1097/01.NAQ.0000264864.94958.8e

[27] Hinshaw, A.S. and Atwood, J.R. (1984) Anticipated Turnover among Nursing Staff Study: Final Report: National Center for Nursing Research. National Institute of Health, Bethesda.

[28] Fornell, C. and Larcker, D.F. (1981) Evaluating Structural Equation Models with Unobservable Variables and Measurement Error. Journal of Marketing Research, 18, 39-50. https://doi.org/10.1177/002224378101800104

[29] Brooks, B.A. and Anderson, M.A. (2005) Defining Quality of Nursing Work Life. Nursing Economics, 23, 319-326, 279.

[30] Khanni, A., Jaafarpour, M. and Dyrekvandomogadam, A. (2008) Quality of Nursing Work Life. Journal of Diagnostic Research, 2, 1169-1174.

[31] Alhusaini, H.A. (2006) Obstacles to the Efficiency and Performance of Saudi Nurses at the Ministry of Health, Riyadh Region: Analytical Field Study. Ministry of Health. Riyadh.

[32] Alotaibi, M. (2008) Voluntary Turnover among Nurses Working in Kuwaiti Hospitals. Journal of Nursing Management, 16, 237-245. https://doi.org/10.1111/j.1365-2834.2007.00802.x 


\section{Appendix}

\section{Please Mark $\square$ in the appropriate column:}

Quality of Nursing Work Life Questionnaire

\begin{tabular}{ccc}
\hline Questions & $\begin{array}{c}\text { Strongly Moderate } \\
\text { Disagreed Disagreed }\end{array}$ & Misagreed \\
Agree & $\begin{array}{c}\text { Moderate Strongly } \\
\text { Agree Agree }\end{array}$
\end{tabular}

\section{Work Life/Home Life Dimension}

I am able to balance work with my family needs.

I am able to arrange for child-care when I am at work.

I have energy left after work.

I feel that rotating schedules negatively affect my life.

My organization's policy for family-leave time is adequate.

I am able to arrange for day care for my elderly parents.

I am able to arrange for day care when my child is ill.

\section{Work Design Dimension}

I receive a sufficient amount of assistance from unlicensed support personnel.

I am satisfied with my job.

My workload is too heavy.

I have autonomy to make patient care decisions.

I perform many non-nursing tasks.

I experience many interruptions in my daily work routine.

I have enough time to do my job well.

There are enough RNs in my work setting.

I am able to provide good quality patient care.

I receive quality assistance from unlicensed support personnel.

\section{Work Context Dimension}

I am able to communicate well with my nurse manager/supervisor.

I have adequate patient care supplies and equipment.

My nurse manager/supervisor provides adequate supervision.

Friendships with my co-workers are important to me.

My work setting provides career advancement opportunities

I feel like there is teamwork in my work setting.

I feel like I belong to the "work family".

I am able to communicate with other therapists (physical, respiratory, etc.).

I receive feedback on my performance from my nurse manager/supervisor.

I am able to participate in decisions made by my nurse manager/supervisor. 


\section{Continued}

I feel respected by physicians in my work setting. The nurses' lounge/break area/locker room in my setting is comfortable.

I have access to degree completion programs through my work setting.

I receive support to attend in-services and continuing education programs.

I communicate well with the physicians in my work setting.

I am recognized for my accomplishments by my nurse manager/supervisor.

Nursing policies and procedures facilitate my work.

I feel the security department provides a secure environment.

I feel safe from personal harm (physical, emotional, or verbal) at work.

I feel that upper-level management has respect for nursing.

\section{Work World Dimension}

I believe that, in general, society has the correct image of nurses.

My salary is adequate for my job given the current job market conditions.

I would be able to find the same job in another organization with about the same salary and benefits. I feel my job is secure.

I believe my work impacts the lives of patients/families.

$\square$

$\square$

$\square$

$\square$

$\square$ 